\title{
Presentación
}

\section{Revisitando la agenda de la seguridad en América Latina}

"El panorama en materia de seguridad en América Latina ha experimentado transiciones significativas en el último lustro. En muchos de nuestros países, cada vez nos sentimos más inseguros y tenemos la certeza de aproximarnos a una debacle en seguridad. Nunca antes estuvimos peor".

El párrafo anterior encabezó la convocatoria para que académicos de distintas geografías nos enviaran sus reflexiones sobre el tema de las políticas de seguridad en América Latina. Fue en el tiempo previo a la pandemia. Escribimos esta presentación en un contexto que ha cambiado más de lo que podíamos imaginar y donde, en muchos lugares de la región latinoamericana, las tentaciones populistas y de los cuerpos de seguridad para controlar la movilidad nos hacen volver a la frase que escribimos en un tiempo que ya nos resulta lejano: "nunca antes estuvimos peor".

Sabemos que antes y ahora existe un reposicionamiento del tema de seguridad en la agenda pública, política y mediática y nuevas aristas significativas del debate emergen en torno a él. Parece que muchos gobernantes están decididos a atacar los virus biológicos y los "virus" de la recesión económica que se avecina, a punta de remilitarizaciones y discursos de miedo y control. Los textos que presentamos muestran cómo ciertos actores sociales se han posicionado en un lugar privilegiado en el espacio público y cómo algunos relatos sobre la seguridad han conseguido una mayor aceptación y legitimidad social.

Antes pensábamos en la mano dura como una respuesta a la cuestión securitaria que se impuso con fuerza en diversos países de la región, como Honduras, Brasil o Colombia, o en la legitimación del ejército como actor fundamental que debe ser repensado en sus facultades, ya no para defender de amenazas extranjeras a los territorios, sino para atender cuestiones de seguridad en los territorios urbanos, como se ha insistido en México, Argentina o El Salvador. Hoy nos encontramos con una agenda de seguridad que se cruza con medidas de higienismo decimonónicas y con fuerzas punitivas y totalitarias del modelo que Donald Trump ha exportado en pleno siglo XXI. Muchos de esos relatos constituyen expresiones del apoyo público a policías que asesinan ilegalmente a delincuentes, de políticas públicas orientadas a criminalizar el espacio público y de protocolos que facultan a las fuerzas federales a disparar a delincuentes en fuga. 
Este número especial de Revista CS ha querido identificar y problematizar distintas prácticas, comportamientos y experiencias que se observan en el nuevo giro punitivo que azota a la región latinoamericana.

El Informe de Desarrollo Humano 2019 reflexiona sobre las desigualdades y presenta a América Latina como un continente profundamente desigual. Sin embargo, incluso en aquellos países que han conseguido disminuir la brecha, los problemas de seguridad se sitúan como una preocupación central. Así, a pesar de que existen entre ellos enormes diferencias en las tasas de homicidio y de otros delitos, las percepciones de lo inseguro han ido en aumento en todos los países de la región. Según Latinobarómetro (2018), ante la pregunta sobre el temor a ser víctima de un delito con violencia, un $39 \%$ dice tener temor todo el tiempo o casi todo el tiempo, es decir, la violencia criminal es un tema presente en la cotidianeidad de los ciudadanos, aun cuando no hayan sido víctimas recientemente. En este contexto, el populismo punitivo ha ingresado con fuerza arrolladora en América Latina.

Con el pretexto de luchar contra la inseguridad, ya sea política, delincuencial o ahora biológica, este populismo punitivo aprovecha la poca confianza de los ciudadanos en la efectividad del aparato judicial y se expande sin muchos miramientos. Políticas de mano dura o tolerancia cero, esto es, medidas extraordinarias como la captura y el encarcelamiento sin juicio, se vuelven ordinarias y se propagan como relatos legítimos, a pesar de que distintas investigaciones han mostrado que, lejos de disminuir las tasas delictivas, dichas políticas incrementan el odio y la violencia. En esta disputa por el sentido de la seguridad, los medios de comunicación son enunciadores privilegiados y han logrado ejercer la presión de lo urgente, es decir, allanar el camino para aquellos políticos que ganan votos con estas propuestas del orden.

En este contexto, pensamos en presentar los artículos intercalados geográficamente para, de algún modo, dar cuenta de la polisemia del concepto de seguridad en relación con los distintos territorios. No obstante, encontramos tres ejes temáticos que tomaremos como puntos de reflexión para esta presentación. En primer lugar, distintos artículos trabajan sobre el crimen organizado: los textos presentan distintos panoramas que abren una mirada más allá de la militarización y el endurecimiento penal como únicas salidas frente al tema. Así, la antropóloga Sabina Frederic se propone mostrar la continuidad entre gobiernos de signo político opuesto en la enunciación de la fragilidad del Estado en la frontera norte argentina, donde las amenazas asociadas con el narcotráfico y el terrorismo internacional degradan la soberanía estatal.

La debilidad estatal como respuesta al crimen organizado se evidencia también en la investigación de Sofía Vizcarra, Diana Bonilla y Bertha Prado, quienes muestran que, a pesar de distintas normativas, el Estado tiene grandes dificultades para sostener una política eficiente de control y lucha contra las organizaciones criminales en el Perú. 
Jesús Bojórquez-Luque, Manuel Ángeles y Alba Gámez proponen, por su parte, observar el fenómeno desde otra perspectiva. Su artículo indaga sobre los modos en que la amenaza del crimen organizado hacia el funcionamiento de las cadenas hoteleras internacionales en el corredor turístico de Los Cabos (Baja California Sur, México) ha promovido esquemas de videovigilancia gubernamentales y la criminalización de actos que, se considera, atentan contra los intereses turísticos en la zona.

El segundo gran tema que abordan transversalmente diversos artículos es el avance del punitivismo y las políticas de mano dura en la región. En los últimos años, asistimos en América Latina a un enconamiento de gobiernos autoritarios y propensos a establecer medidas de endurecimiento penal, de represión de los movimientos sociales y de exaltación de miradas homofóbicas, racistas y autoritarias sobre las poblaciones. En este sentido, el trabajo de Aramis Lascano y Joaquín Vélez nos permite pensar el punitivismo más allá de los comportamientos policiales para visualizar las disputas por las formas de control de la oferta de sexo en el espacio público. Así, los autores proponen la figura de circuitos punitivos para visualizar las especificidades territoriales vinculadas a la inseguridad que tienen las prácticas de control moral y penal sobre la llamada zona roja en Argentina, y la multiplicidad de personas y agencias que intervienen en su curso.

La evolución de la demanda de mayores castigos hacia los delincuentes en la opinión pública ha sido analizada por María Alejandra Otamendi en este dossier. La investigadora encuentra que, en el Área Metropolitana de Buenos Aires (AMBA), la reacción punitiva se corresponde relativamente con los niveles de amenaza securitaria y se potencia a partir de casos que causan conmoción y se politizan en el espacio público.

Frente a los discursos punitivistas que circulan en la región latinoamericana, una de las soluciones que los gobiernos proponen y las sociedades aceptan se relaciona con el encarcelamiento. Así, Inés Mancini recupera con originalidad esta impronta para mostrar algunos de los efectos del encarcelamiento que se extienden, incluso, más allá de los penados.

Como enunciamos unas líneas arriba, los medios de comunicación construyen acontecimientos y colaboran en la formación de ciertas percepciones sociales. La relación entre medios de comunicación, migración y delito ha sido analizada en este número por Lucía Dammert y Matthias Erlandsen. Mediante un análisis de contenido, los autores muestran que la generalización de imágenes estigmatizadoras y la consolidación de la metáfora que vincula la migración con el peligro, principalmente con la criminalidad, es una operación recurrente en la construcción de las noticias. Para los autores chilenos, estas coberturas permiten enfatizar imágenes amenazantes y políticamente rentables que muestran un discurso político centrado en el populismo punitivo. 
También a partir del análisis de periódicos y semanarios de importancia nacional, Andrea Mejía-Jerez, Álvaro Acevedo-Tarazona y Andrés Correa-Lugos analizan los modos en que el discurso de la seguridad nacional se consolidó como hegemónico en la prensa de Bucaramanga en la década de los ochenta. Sin duda, en la tensión producida por el conflicto armado y el narcotráfico, Colombia es uno de los países que más ha sufrido las políticas securitarias de control social y mano dura.

Por último, las fuerzas de seguridad, en especial el rol de la policía como agente del control social, es otro de los temas de análisis que aborda este dossier. Tanto el trabajo de Déborah Goldin como el de Mariana Galvani y Mariana Lorenz le dan voz en sus artículos a estos actores. Así, Goldin muestra las implicancias de la incorporación de un programa barrial en los procesos de identificación de los(as) suboficiales de la Policía de Córdoba (Argentina) e indaga sobre los modos en que este programa afectó a quienes se incorporaron a esta dependencia, con lo cual problematiza los modos de intervención policial legítimos y las aptitudes deseables de un policía, entre otros elementos.

Galvani y Lorenz, por su parte, analizan un fenómeno particular: la transferencia de parte de la Policía Federal Argentina a la Policía de la Capital Federal y las formas en que expresaron su descontento algunos de los expolicías federales incorporados a la nueva policía. Las autoras muestran diferentes formas de manifestación de estos funcionarios, desde agruparse en la calle hasta hacer circular mensajes por redes sociales para oponerse. De esta forma, marcan un punto de inflexión en la forma en que estos actores han sido visibilizados en la esfera pública.

En síntesis, algunos artículos jerarquizan problemáticas, analizan y proponen soluciones para el problema de la seguridad, pero también promueven el surgimiento de nuevos interrogantes en el campo de investigación vinculado con los estudios de seguridad ciudadana. ¿Qué consecuencias conlleva un mayor policiamiento y una nueva visibilidad de las fuerzas armadas en la región? ¿Cómo se construyen los procesos discriminatorios y excluyentes de un otro peligroso (migrante, joven varón y pobre, etc.)? ¿Cuáles son las tácticas que implementan los ciudadanos en su gestión cotidiana de la seguridad? ¿De qué modos inciden los medios de comunicación y otras fuentes de información en la configuración de sociedades inseguras? ¿Cómo repercute la inseguridad como problema público en las campañas políticas y en la elección de candidatos conservadores? No tenemos respuestas contundentes, pero, sin duda, en este número se encuentran elementos para sumar a este debate.

Brenda Focás (Universidad Nacional de San Martín, Argentina)

Amparo Marroquín-Parducci (Universidad Centroamericana

José Simeón Cañas, El Salvador)

\section{Editoras invitadas}

Mayo de 2020 